\title{
CHEMOMETRIC-BASED ELECTRONIC NOSE APPLICATION TO PORK OIL AND OLIVE OIL USING THE ODOR PATTERN CLASSIFICATIONS
}

\author{
Imam Tazi $^{*}$, Muthmainnah ${ }^{1}$, Suyono $^{2}$, Avin Ainur ${ }^{3}$, Fajrul Falah ${ }^{1}$, Arum Sinda Santika ${ }^{1}$ \\ ${ }^{1}$ Department of Physics,Science, and Technology of Faculty, Maulana Malik Ibrahim Malang \\ Gajayana St. No. 50 Malang 65144 \\ ${ }^{2}$ Department of Biology,Science, and Technology of Faculty, Maulana Malik Ibrahim Malang \\ Gajayana St. No. 50 Malang 65144 \\ ${ }^{3}$ School of Medicine, Faculty of Medicine and Health Science, Maulana Malik Ibrahim Malang \\ Gajayana St. No. 50 Malang 65144 \\ Recieved: $10^{\text {th }}$ April 2018; Revised: $19^{\text {th }}$ April 2018; Accepted: $28^{\text {th }}$ April 2018
}

\begin{abstract}
A chemometric-based electronic nose has designed for analyzing pork oil andolive using the odor pattern classifications of a chemometric-based electronic nose. The electronic nose (e-nose) built from a combination of several chemical sensors derived from a semiconductor. The data retrieval was done by vaporizing the sample, then being captured by the sensor and identified by the electronic nose (enose). The output data from the electronic nose is the voltagereleased by each sensor.Samples analyzed were $100 \%$ olive oil, $100 \%$ pork oil and a combination of olive oil and pork oil with a ratio of $50 \%$ : $50 \%$. The result of pattern classification using linear discriminant analysis (LDA) method shows that each sample is clustered well with the percentage of first discriminant function value is $87,9 \%$ and second discriminant function is $12,1 \%$.
\end{abstract}

Keywords:electronic nose; LDA; pork oil; olive oil

\section{Introduction}

Cooking oil is one of the basic needs of human beings to fulfill daily needs. Currently, Challenge analysis to detect the original cooking oil and the presence of pork oil contaminants to be the attention of researchers. Thechemometric based classification method can identify the quality of olive oil by determining the taste, the smell of musty, rancid and rancid. ${ }^{1}$ The combination of FTIR tools and chemometric methods to determine the pattern classification of various animal oils and vegetable oils has been able to improve the quality of classification patterns. ${ }^{2}$ Detecting the authenticity of vegetable oils using GCMS can be used to analyze fatty acid compositions and fatty acid profiles. ${ }^{3}$

\footnotetext{
*Corresponding author.

E-Mail: imamtazi@yahoo.com
}

Olive oil is an oil made from olives and has a high unsaturated fat value that is beneficial to health. ${ }^{4}$ Besides, it has highnutritional value; its price is also high and often falsified. ${ }^{5}$ The combination of semiconductor sensors can distinguish 141 samples labeled olive oil.The LDA method can classify original and non-native olive oils with a $95 \%$ accuracy level. ${ }^{6}$ The quality of olive oil has been investigatedon howcontamination of chemicals and bacteria during olive storage. ${ }^{7}$ Ultraviolet light is used to alter the olive oil scent to be rancid and able to be evaluated based on the degree of rancidity with a combination of sensors on the electronic nose. ${ }^{8}$

The e-nose is an electronic olfactory system that has an aroma-based work system. ${ }^{9}$ The smell or aroma detected by the sensor will be processed and will form a 
unique voltage change pattern for each sensor. ${ }^{10}$ The e-nose mimics the human sense of smell. The human sense of smell system divides into three layers. The first layer is a layer of olfactory cells that amount to about one billion cells. The second layer is an olfactory vesicle that serves to regulate, strengthen and control messages from olfactory cells. The third layer is the olfactory center located in the brain and is responsible for defining signals and classifying the types of smells. ${ }^{11}$ E-noses are made of semiconductor sensors arranged in parallel.It has been developed and widely used in the food industry. ${ }^{12,13,14}$

Some research on cooking oil using enose aim to gain a fast and cheap method. The e-nose consists of 18 arrays of MOS metal sensors used to detect the degree of rancid sunflower oil. ${ }^{15}$ Itcan distinguish olive oil from different regions of Morocco based on its volatile profile. ${ }^{16}$ It also has been successfully developed to distinguish pig fat from other fats as well as mixed fat using surface acoustic wave (SAW). ${ }^{17}$

Chemometrics is a combination of statistical and mathematical methods for designing optimum procedures in providing informations contained in a data. Chemometricsused to classify citrus fruit flavors with a major component value of $88.6 \%{ }^{18}$.Several types and brands of dairy products have been classified using chemometrics with a value of $90.5 \% .^{19}$

Linear discriminant analysis (LDA) is a multivariate statistical technique that can classify objects into a particular group.The identification objects patterncan be determined by finding discriminant value in whichits value can numerically classify the observed objects. The LDA technique classified the taste change of cowmilk $100 \%$ and $98.6 \%$ goat milk when measured by using the electrical nose. ${ }^{20}$

\section{Methods}

Data collection was done by preparing each sample in measuring cup as much as 50 $\mathrm{ml}$. The e-nose chamber insertedinto a measuring cup, and the sample heated to a temperature of $60^{\circ} \mathrm{C}$. Each sensor in the enose measured the scent on each sample. Measurements on each sample were performed with ten repetitions with the sensing technique (duration 30 seconds), fleshing (duration 30 seconds) and sampling 1 data / second.

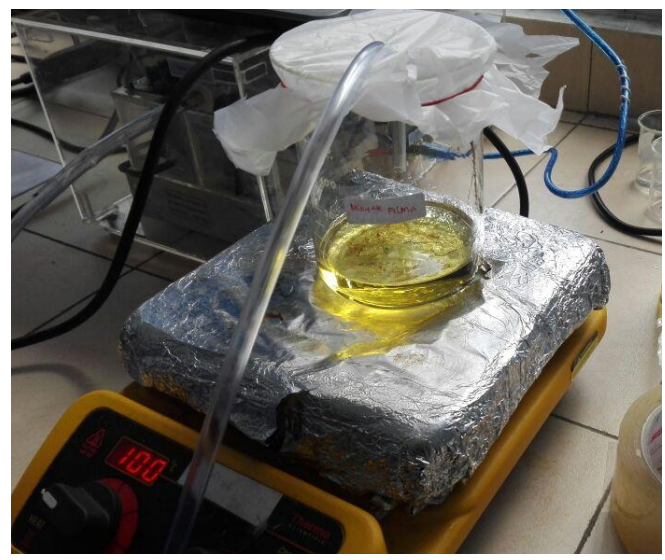

Figure 1. The process of taking data on the electronic nose

The sensor output data is analog data.Before displayed on the computer then first converted to digital using Analog Digital Converter (ADC).



Figure 2. Display the output of the electronic nose

Figure 2 is an example of output view on sampling data from process sensing, fleshing and sampling. Preprocessing data was done by searching for the extent of the sensingfleshing results in the steady-state data and done by the baseline method. The result of measurement is numerical data then 
processed by linear discriminant analysis method (LDA).

\section{Result and Discussion}

The e-nose constructed from an array of sensors using chemosensor. Chemosensor is a device that can convert chemical quantities into electrical signals. The concentrations change of specific particles such as atoms, molecules, ions in gas or fluid phases can alter the chemosensor electrical signals. It is also capable ofdetecting odor molecules in gas phases in the form of volatile organic molecules with relatively different molar masses.

The electrical properties changes of the sensor are due to the interaction between semiconductors and gas molecules. The oxygen gas molecules that penetrate the semiconductor material will capture electrons in the conduction band. The interaction between the semiconductor material and the reduced gas results in an increase in concentration represents in the following chemical reactions:

$$
\begin{aligned}
& e+\frac{1}{2} O_{2} \rightarrow O(s)^{-} \\
& X(g)+O(s)^{-} \rightarrow X O(g)+e
\end{aligned}
$$

$\mathrm{S}$ is the surface, $\mathrm{g}$ is the gas phase, e is the electron of the conduction band on metal oxide semiconductor, and $\mathrm{X}$ is the reducible gas.Eq. (1) shows the oxygen absorbed in the hole of the oxide semiconductor.The conductivity of a semiconductor decreases when oxygen is absorbed.The electron is derived from the reduced gas of the oxygen ions reaction to the gas $\mathrm{X}(\mathrm{g}) .^{21}$

Table 1. Sensor output on olive oil samples

\begin{tabular}{ccccccccccc}
\hline \multirow{2}{*}{ Name } & \multicolumn{10}{c}{ Output Sensor $(\mathrm{mV})$} \\
\cline { 2 - 11 } & 1 & 2 & 3 & 4 & 5 & 6 & 7 & 8 & 9 & 10 \\
\hline Olive oil 1 & 251,8 & 374,4 & 239,6 & 229,1 & 243,0 & 909,7 & 138,0 & 240,1 & 138,3 & 140,3 \\
Olive oil 2 & 275,5 & 402,6 & 238,2 & 227,2 & 241,1 & 908,4 & 137,3 & 238,5 & 137,4 & 147,4 \\
Olive oil 3 & 273,6 & 409,2 & 234,8 & 223,7 & 238,0 & 901,5 & 136,0 & 235,1 & 136,1 & 151,5 \\
Olive oil 4 & 282,2 & 424,2 & 234,3 & 223,1 & 237,5 & 896,0 & 135,9 & 234,5 & 135,9 & 159,3 \\
Olive oil 5 & 264,7 & 407,3 & 233,7 & 222,4 & 236,9 & 893,9 & 135,6 & 233,9 & 135,5 & 148,9 \\
Olive oil 6 & 251,7 & 385,4 & 241,8 & 230,9 & 244,3 & 896,4 & 138,6 & 241,3 & 138,7 & 141,1 \\
Olive oil 7 & 255,5 & 392,6 & 237,5 & 226,4 & 240,4 & 894,8 & 137,0 & 237,5 & 137,1 & 139,7 \\
Olive oil 8 & 263,4 & 390,3 & 236,0 & 224,9 & 238,9 & 894,9 & 136,6 & 236,2 & 136,4 & 142,6 \\
Olive oil 9 & 226,5 & 370,6 & 238,4 & 227,2 & 241,1 & 891,5 & 137,4 & 238,3 & 137,4 & 139,4 \\
Olive oil 10 & 246,0 & 408,0 & 236,7 & 225,6 & 239,8 & 891,0 & 136,7 & 236,8 & 136,9 & 139,9 \\
\hline
\end{tabular}

Table 2. Sensor output on pork oil samples

\begin{tabular}{ccccccccccc}
\hline \multirow{2}{*}{ Name } & \multicolumn{10}{c}{ Output Sensor $(\mathrm{mV})$} \\
\cline { 2 - 11 } & 1 & 2 & 3 & 4 & 5 & 6 & 7 & 8 & 9 & 10 \\
\hline Pork oil 1 & 191,3 & 349,2 & 242,4 & 231,9 & 245,7 & 901,0 & 139,1 & 242,8 & 139,6 & 141,5 \\
Pork oil 2 & 209,4 & 340,3 & 237,6 & 227,1 & 241,3 & 898,1 & 137,2 & 237,9 & 137,3 & 139,6 \\
Pork oil 3 & 216,1 & 340,9 & 236,9 & 226,3 & 240,9 & 896,1 & 136,9 & 237,3 & 137,2 & 139,4 \\
Pork oil 4 & 163,3 & 270,0 & 244,1 & 233,6 & 247,5 & 907,8 & 140,3 & 244,4 & 140,4 & 142,5 \\
Pork oil 5 & 189,7 & 276,6 & 242,8 & 232,4 & 246,6 & 911,0 & 139,7 & 243,2 & 140,0 & 142,0 \\
Pork oil 6 & 198,4 & 281,0 & 242,0 & 231,7 & 245,9 & 911,0 & 139,5 & 242,5 & 139,7 & 141,7 \\
Pork oil 7 & 187,6 & 286,8 & 241,7 & 231,2 & 245,5 & 910,1 & 139,4 & 242,2 & 139,5 & 141,6 \\
Pork oil 8 & 201,6 & 290,1 & 241,3 & 230,8 & 245,0 & 906,5 & 139,2 & 241,7 & 139,4 & 141,4 \\
Pork oil 9 & 186,1 & 292,4 & 240,8 & 230,2 & 244,6 & 906,7 & 139,1 & 241,2 & 139,2 & 141,2 \\
Pork oil 10 & 172,2 & 294,3 & 240,7 & 230,2 & 244,5 & 905,4 & 139,0 & 241,1 & 139,1 & 141,1 \\
\hline
\end{tabular}


Table 3. Sensor output oncombination of pork oil and olive oil

\begin{tabular}{|c|c|c|c|c|c|c|c|c|c|c|}
\hline \multirow{2}{*}{ Name } & \multicolumn{10}{|c|}{ Output Sensor (mV) } \\
\hline & 1 & 2 & 3 & 4 & 5 & 6 & 7 & 8 & 9 & 10 \\
\hline Pork oil +olive oil 1 & 185 & 260 & 245 & 235 & 248 & 899 & 140 & 245 & 140 & 142 \\
\hline Pork oil +olive oil 2 & 185 & 262 & 242 & 232 & 246 & 898 & 139 & 243 & 139 & 141 \\
\hline Pork oil +olive oil 3 & 182 & 261 & 241 & 231 & 245 & 897 & 138 & 241 & 139 & 141 \\
\hline Pork oil +olive oil 4 & 178 & 265 & 241 & 230 & 244 & 903 & 138 & 241 & 139 & 141 \\
\hline Pork oil +olive oil 5 & 188 & 265 & 240 & 230 & 244 & 901 & 138 & 240 & 138 & 141 \\
\hline Pork oil +olive oil 6 & 179 & 267 & 240 & 229 & 244 & 899 & 138 & 240 & 138 & 141 \\
\hline Pork oil +olive oil 7 & 189 & 269 & 239 & 229 & 243 & 901 & 138 & 240 & 138 & 140 \\
\hline Pork oil +olive oil 8 & 187 & 263 & 242 & 232 & 246 & 900 & 139 & 243 & 139 & 142 \\
\hline Pork oil +olive oil 9 & 202 & 289 & 242 & 232 & 246 & 902 & 139 & 242 & 139 & 141 \\
\hline Pork oil +olive oil 10 & 182 & 291 & 240 & 230 & 244 & 901 & 138 & 241 & 139 & 141 \\
\hline $\begin{array}{l}\text { ensor measured the sar } \\
\text { herefore, in one mea }\end{array}$ & & & & & th &  & 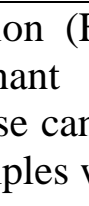 & ell. & $2.1 c$ & $\begin{array}{l}\text { The } \\
00 \% \\
\text { mple }\end{array}$ \\
\hline
\end{tabular}
represent the output voltage sensors on the enose. Each data repetition has almost the same value for each oil sample. It is evident from the data that the output of the sixth sensor has a high voltage value. The average output voltage was $900 \mathrm{mV}$.

Each sensor provides different measurements for each sample, so there are many graphs to be analyzed. Multivariant techniques are applied to evaluate the response capability of the electronic nose. Linear discriminant analysis (LDA) is chosen to evaluate the response so that the electronic nose measurement output can be well classified.

The LDA score plot is used to visualize the data classification of odor patterns from some cooking oils. Its plots sketchedin 2dimensional graphs. The score chart coordinate consists of the discriminant function 1 and discriminant function 2 representing the data variant of the overall test result data.

Based on Figure 3, it can be classified into 3 groups. Group 1 is the result of olive oil sample classification; group 2 is the result of the classification of the sample of pork oil; group 3 is the result of the mixed classification of olive oil and pork oil. The value of the first discriminant function (FD1) is $87.9 \%$ and the value of the second
Moreover, it also appears that in group 1 the data is somewhat diffused from its centroid center. The diffusion represents that olive oil samples were well clustered. Group 2 has a broader diffusion rate comparing group 1. On the other hand, group 3has the smallest dispersion rate. However, there is one data that goes across to group 2. It occurred in such a way that because the crossed sample indeed contains pork oil mixings.

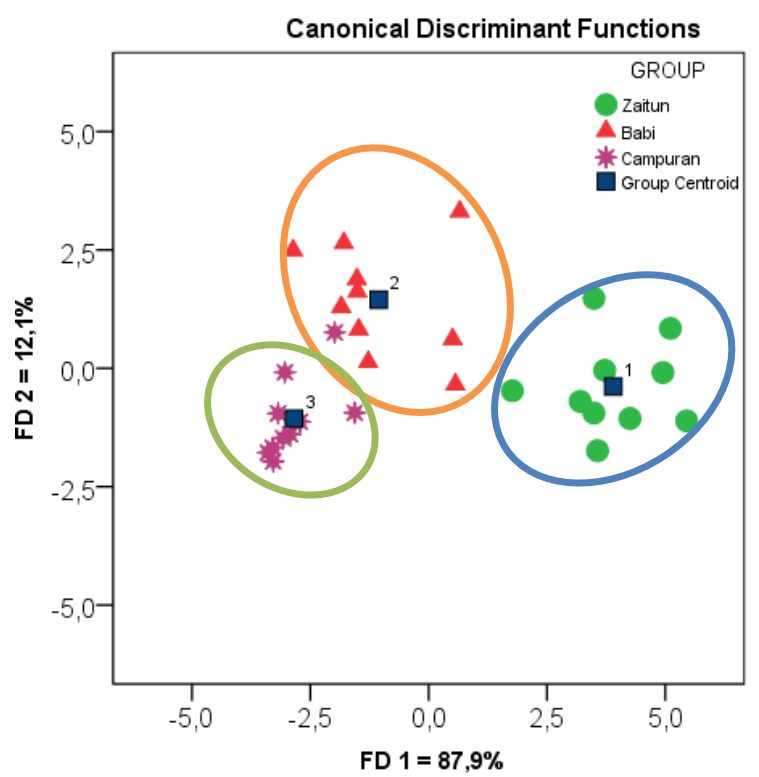

Figure 3. The LDA Score plotsof each sample 


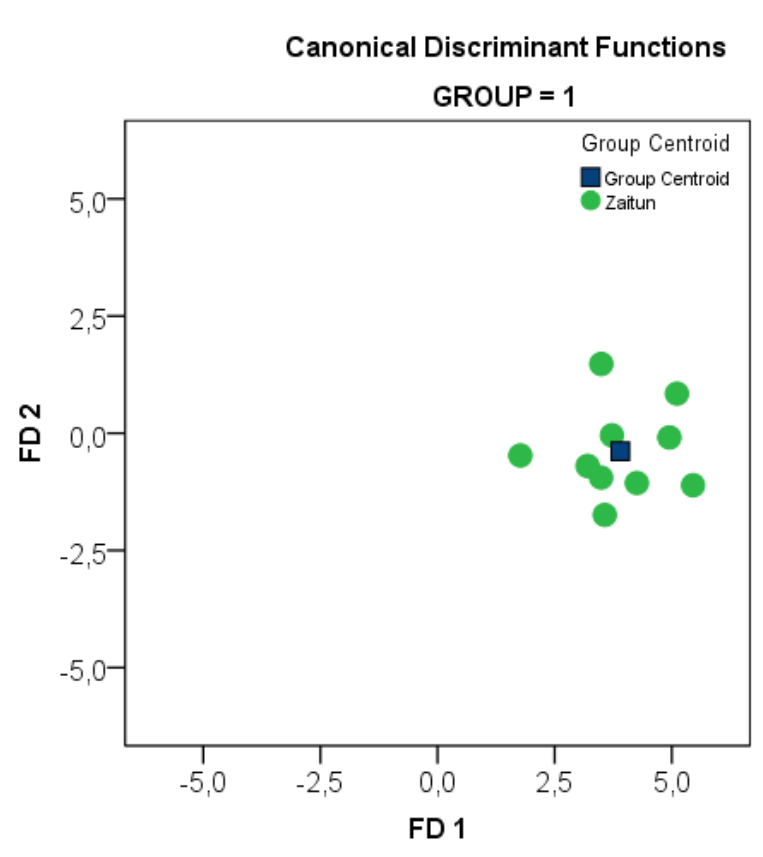

Figure 4. Score plot of LDA Olive Sample

The olive oil centroid data in Fig. 4 is around the coordinates $(4,-0.5)$. Olive oil measurement data spread around the centroid data. Fourdata that spread far from the centroid and six data gathered near the centroid. Itshows that $40 \%$ of olive oil measurements have a considerable deviation value.

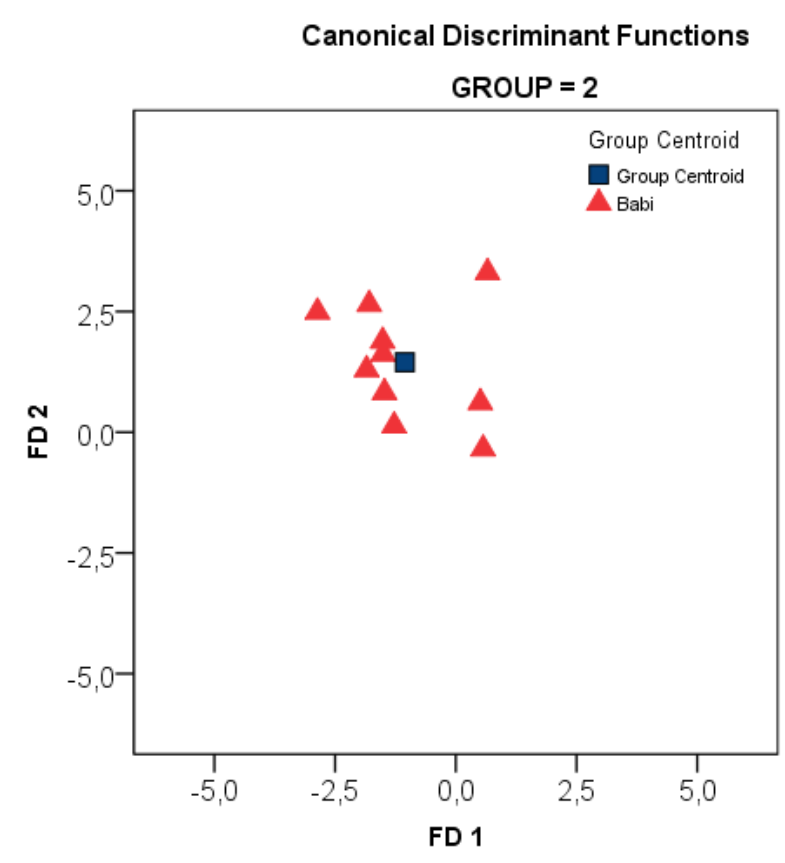

Figure 5. Score plot of LDA pork oil Sample
Moreover, the centroid data of pork oil in Fig. 5is located around the coordinates (1,1.5). Pork oil measurement data spread around the centroid data. Six data that spread far from the centroid and 4 data gathered near the centroid. It shows that $60 \%$ of the results of the measurement of pork oil have a considerable deviation value.

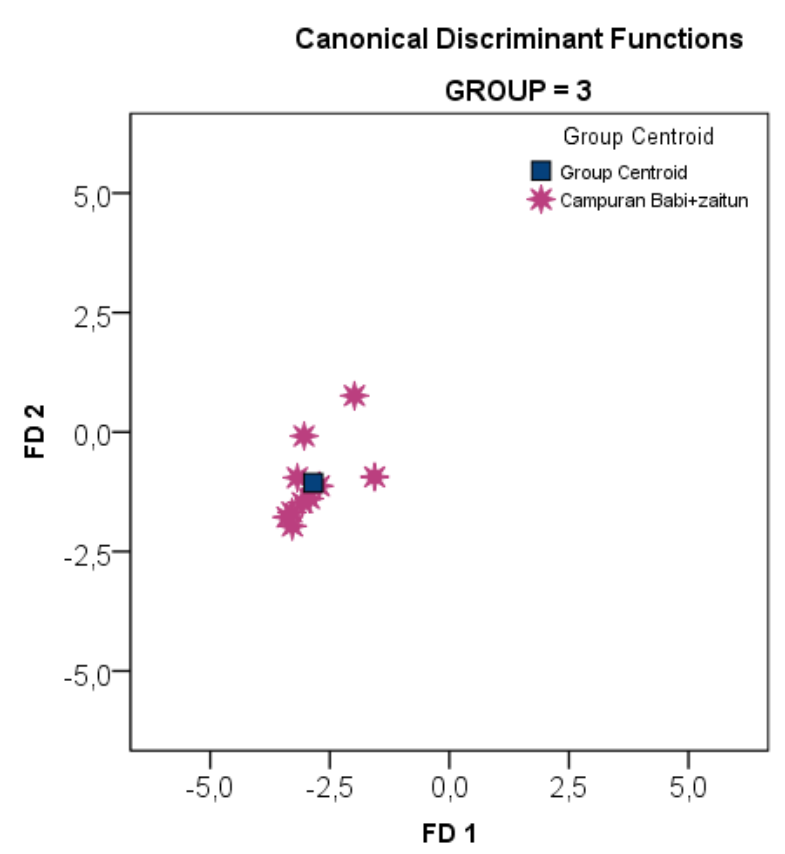

Figure 6. Score plot of LDA combination of pork oil and olive oil

In Fig. 6, the centroid data of a mixture of pork oil and olive oil are around the coordinates $(-2.4,1.5)$. Measurement data for a mixture of pork oil and olive oil spread around the centroiddata. Two data that spread far from the centroid and eight data gathered near the centroid. Itshows that $20 \%$ of the results of the measurement of pig oil have a considerable deviation value.

The e-nose works based on changes in the concentration of a particle such as atoms, molecules or ions in the gas and then converted to electrical signals. Sensors made of semiconductor materials on the electronic nose will absorb oxygen during interacting with gas and capture electrons in the conduction band. Changes in gas composition in the sample will change the electrical signal on the electronic nose. 
The e-nose can distinguish pig-containing oil. Samples containing pork oil form a separate group of oils that are free ofpork oil contamination. Pure olive oil has a distinctive aroma so that the e-nose can distinguish it from other oils. ${ }^{22}$ The electronic nose can be used as a way to detect oil content of pork on cooking oil.

\section{Conclusion}

Based on the LDA scores plots, Thee-nose can distinguish olive oil samples, pork oil and olive oil mixture and pigs well.Each sample clustered well enough with discriminant function $187,9 \%$ and second discriminant function $12,1 \%$.

\section{References}

1. Borràs, E. et al. Olive oil sensory defects classification with data fusion of instrumental techniques and multivariate analysis ( PLS-DA ). Food Chemistry journal. 2016; 203: 314-322.

2. Che Man, Y.B., Rohman, A. \& Mansor, T.S.T. Differentiation of lard from other edible fats and oils by means of Fourier transform infrared spectroscopy and chemometrics. JAOCS, Journal of the American Oil Chemists' Society. 2011; 88(2): 187-192.

3. Li, X. et al., A combination of chemometrics methods and GC-MS for the classification of edible vegetable oils. Chemometrics and Intelligent Laboratory Systems. 2016; 155: 145150.

4. SH Bintari, K Nugraheni.Decreased Blood Sugar Levels Due to Extra Virgin Olive Oil (Study in the High Fat-Induced Sprague Dawn's Raised Wheat Rat).Jurnal MIPA. 2012; 35 (2):116121.In Indonesia

5. Smejkalova, D.; Piccolo, A. High-power gradient diffusion NMR spectroscopy for the rapidassessment of extra-virgin olive oil adulteration. Food Chem. 2010; 118: 153-158.

6. Gonzalez Martin, Y.; Cerrato Oliveros, M.C.; Perez Pavon, J.L.; Garcia Pinto,
C.; Moreno Cordero, B. Electronic nose based on metal oxide semiconductor sensors and pattern recognition techniques: characterisation of vegetable oils. Anal Chim Acta. 2001; 449: 69-80.

7. Garcia-Gonzalez, D.L.; Aparicio, R. Detection of vinegary defect in virgin olive oils by metal oxide sensors. J. Agric. Food Chem. 2002, 50, 18091814.

8. Garcia-Gonzalez, D.L.; Aparicio, R. Detection of defective virgin olive oils by metal-oxide sensors. Eur Food Res Technol. 2002; 215: 118-123.

9. Danang Lelono, Muhammad Arifianto Chairiawan. Characterization of Aroma Salak Pondoh Pattern with E-Nose Sensor Metal Oxide Based. IJEIS. 2013 ;3 April 1:71-82.

10. Scott, S.M., Data Analysis for Electronic Nose Systems, MicrochimActa. 2006; 156: $183-207$

11. Botre, B.A., Gharpure, D.C. \& Shaligram, A.D. Sensors and Actuators B : Chemical Embedded Electronic Nose and Supporting Software Tool for its Parameter Optimization. Sensors \& Actuators: B. Chemical. 2010; 146(2): 453-459.

12. J. Trihaas, P.V. Nielsen. Electronic nose technology in quality assessment: monitoring the ripening process of Danish blue cheese. J Food Sci. 2005; 70: 44 49.

13. M. Peris, L.E. Gilabert. A 21st century technique for food control: electronic noses. Anal Chim Acta. 2009; 638: 115.

14. H. Guohua, W. Lvye, M. Yanhong, Z. Lingxia. Study of grass carp (Ctenopharyn-godonidellus) quality predictive model based on the electronic nose. SensActuators B: Chem. 2012; 35: 301-308.

15. Upadhyay, R., Sehwag, S. \& Mishra, H.N. Frying disposal time of sun fl ower oil using hybrid electronic nose- fuzzy logic approach. LWT - Food Science and Technology.2017; 78: 332-339.

16. Haddi, Z. et al. Discrimination and 
identification of geographical origin virgin olive oil by an e-nose based on MOS sensors and pattern recognition techniques. Procedia Engineering. 2011; 25:1137-1140.

17. Nurjuliana, M., Che Man, Y.B. \& Mat Hashim, D. Analysis of lard'saroma by an electronic nose for rapid Halal authentication. JAOCS, Journal of the American Oil Chemists' Society. 2011; 88(1):75-82.

18. Bagas Surya Wibowo, Imam Tazi, Kuwat Triyana, Pengembangan Sistem Sensor Rasa Berbasis Membran Selektif Ion Untuk Klasifikasi Buah Jeruk. Jurnal Fisika Indonesia. 2013; 49 (XVII): 9-13.

19. Imam Tazi, Kuwat Triyana, Dwi Siswanta, Anovel Arduino Mega 2560 Microcontroller-Based Electronic Tongue for Dairy Product Classification. AIP Conference Proceedings. 2016; 170003-1 - 170003-5.

20. Imam Tazi, Anis Choiriyah, Dwi Siswanta, Kuwat Triyana. Detection of Taste Change of Bovine and Goat Milk in Room Ambient using Electronic Tongue. Indones.J.Chem.2017; (3);422430.

21. Fraden j. Handbook of Modern Sensors Physics, Designs, And Applications Third Edition.Advanced Monitors Corporation San Diego. California. 2003.

22. Amalia Berna. Metal Oxide Sensors for Electronic Noses and TheirApplication to Food Analysis. Sensor. 2010; 10: 3882-3910. 